\title{
Dom Joaquim Xavier Curado e a política bragantina para as províncias platinas (1800-1808)
}

\section{Francisca Nogueira de Azevedo}

oaquim Xavier Curado é considerado o primeiro militar nascido no Brasil
que conseguiu altos postos no exército colonial. Foi figura central para
a política expancionista portuguesa nas regióes platinas, tanto no período joanino quanto no reinado de Pedro I. Durante vinte anos Xavier Curado foi responsável pela coordenação de uma espécie de "inteligência" portuguesa no Rio da Prata. Seu papel era muito mais de um agente secreto, atuando no serviço de informaçōes e aconselhando estratégias para invasão, do que de comandante militar. Diversas vezes ultrapassou clandestinamente a fronteira para investigar as condiçôes de resistência das colônias espanholas e buscar apoio da população a fim de facilitar a entrada das tropas e a ocupação portuguesa na região. Esse trabalho lhe rendeu inúmeras condecoraçōes e medalhas — ordens Cruzeiro, São Bento, de Aviz, e a mais importante condecoração militar da época, a de comendador da "Ordem da Torre e Espada do Valor, Lealdade e Mérito", recebida por decreto de Dom João VI. Recebeu ainda o título nobiliárquico de barão e o de conde de São João das Duas Barras (1826). Foi Xavier Curado, em sua época, o general que mais comendas recebeu. As insígnias recebidas pelo militar, todas elas provenientes de sua campanha nas fronteiras sul do Brasil, permitem avaliar a importância daquela região no âmbito da política externa bragantina. ${ }^{1}$

Após voltar de uma missão ao sul, Xavier Curado foi indicado pelo então vice-rei, Luiz de Vasconcelos e Souza (1779-1790), para comandar a defesa dos habitantes da região de Parayba-Nova, nos limites da capitania de São Paulo e Minas Gerais, de índios "bravios" que atacavam e saqueavam as fazendas. Foi nessa época que se destacou como grande estrategista militar. Conseguiu formar um corpo de cavalaria auxiliar com os habitan- 
tes da região, controlando a guerra com os índios e garantindo a ocupação permanente dos colonizadores. Com o objetivo de consolidar o sistema de conquista, realizou a divisão da freguesia de São João Marcos em cinco distritos, onde criou corpos de ordenanças com a respectiva oficialidade.

Os sucessos de Xavier Curado na "pacificação" dos conflitos entre índios e brancos no sertão do Rio de Janeiro recomendou-o para uma outra missão, que, dada a sua importância política, exigia habilidade e experiência de seu comandante. Quando, no início do século XIX, a crise entre as coroas ibéricas agudizava as disputas na fronteiras do sul do Brasil, Xavier Curado foi indicado governador de Santa Catariana — local de entrada e distribuição das mercadorias inglesas por toda a América meridional com ordens de fazer incursões secretas ao Rio da Prata para colher informações sobre as forças espanholas na região.

O pleito pelo território platino entre as monarquias ibéricas implicou uma série de tratados internacionais durante o século XVIII, mas nenhum deles conseguiu solucionar de maneira duradoura a questão dos limites entre as terras portuguesas e espanholas na América. ${ }^{2}$ Desde o início da colonização do Brasil os portugueses já cobiçavam a região. $\mathrm{Na}$ expedição colonizadora de 1530, por exemplo, Martim Afonso saiu de Portugal com ordem expressa de fundar uma colônia às margens do Rio da Prata. Protestos e ameaças do governo espanhol fizeram com que o navegador se dirigisse à região um pouco mais acima, fundando a Vila de São Vicente no litoral paulista. Em 1534 a Espanha enviou às províncias do Prata expedição com mil e duzentos homens comandados por Pedro de Mendonça. Os portugueses insistiam na idéia da "fronteira natural" e não desistiam de estender seus limites até o lado esquerdo do estuário do Rio da Prata, especialmente após a ascensão ao trono do rei dom Pedro II (16671705), época em que se fundou a Colônia do Sacramento (1680), cujo principal objetivo era o de marcar a presença lusa naquela parte da América, facilitando a desagregação da dominação espanhola na banda oriental do Rio da Prata. Observa-se que há uma certa continuidade na política externa bragantina em relação aos limites da fronteira sul. A luta pela conquista da banda oriental do Rio da Prata durou quase quatro séculos e consumiu grandes somas do numerário português, sem contar a perda de vidas. 
No meio da disputa luso-espanhola, os interesses britânicos foram um fator complicador nos litígios entre as duas coroas. Documentos comprovam que, desde os meados do século XVIII, a ocupação platina era cada vez mais cogitada pelo gabinete britânico, que contava com o incentivo da agressiva burguesia inglesa e com informações da "inteligência” britânica infiltrada na região. No entanto, as duas investidas frustradas dos ingleses de ocupar, militarmente, primeiro Buenos Aires, depois Montevidéu 1806 e 1807 — , em defesa de interesses mercantis, reforçam a tese de que a ação conjunta com o governo português seria o caminho mais fácil para a conquista da América meridional. O projeto de transmigração da corte para o Brasil, que já vinha sendo arquitetado havia algum tempo pelo Gabinete de St. James, passou a ter prioridade no âmbito da política externa da Grã-Bretanha.

Ao tentar convencer dom João a partir, Lord Strangford, embaixador inglês em Portugal, instruído por seu governo, argumentou em favor da concretização do antigo desejo português de conquistar as colônias espanholas do Rio da Prata. A vinda da família portuguesa para a América pôs em execução o projeto de construção de um amplo império, arquitetado por dom Rodrigo de Souza Coutinho, com o apoio de Lord Canning primeiro ministro de Inglaterra - , e definido na Convenção Secreta de Londres, que previa tornar o Brasil "um empório para suas [dos comerciantes ingleses] mercadorias, destinadas ao consumo de toda a América do Sul”. Na verdade, desde que Canning assume o Ministério das Relações Exteriores, a idéia da transferência da Corte portuguesa para América é uma das finalidades mais relevantes de sua diplomacia, eminentemente comercial. $\mathrm{O}$ ministro vê que a transmigração da corte bragantina, independentemente das justificativas de caráter político, proporcionaria aos exportadores ingleses um contato mais direto com o Brasil, eliminando as burocracias e as complicações da intermediação de Lisboa. Sendo assim, estrategicamente, o controle e ocupação da região platina tornavam-se pontos fundamentais no projeto luso-inglês.

É verdade que a transferência da Corte para a América não foi cogitada somente durante a crise gerada pela invasão francesa da Península Ibérica. Desde o século XVII, no período da Restauração (1640), ela aparece 
nas conversações políticas, volta à pauta no século seguinte, com dom Luís da Cunha e o marquês de Pombal. Novamente se pensaria nessa alternativa por ocasião do terremoto de 1775 e, depois, durante a invasão do país em 1792. Mas foi a Paz de Balê (1795), negociada por Manuel Godoy, poderoso ministro de Carlos IV — rei da Espanha — promovendo a aliança franco-espanhola, que exigiu uma reviravolta diplomática na política externa das monarquias ibéricas, resultando na vinda da família real portuguesa para o Brasil.

O cenário político internacional agravou-se com a vitória da GrãBretanha nas negociações que resultaram no Tratado de Utrecht (1713). A Inglaterra entrou na guerra de sucessão espanhola com objetivo bem definido, como comprovam os termos da negociação de paz: ampliar seu comércio em relação às colônias espanholas na América. Até então o comércio anglo-espanhol era muito mais importante entre Inglaterra e Espanha do que entre a Grã-Bretanha e o Império Hispano-Americano. Na realidade, a paz de Utrecht, assinada em Madri em 23 de março de 1713, ao mesmo tempo que confirmou Felipe $V$ no trono da Espanha, através de concessão do asiento, entregou aos comerciantes britânicos o direito de tráfico negreiro em suas possessões americanas. Este foi o primeiro grande passo dado pela Inglaterra em direção à preponderância mundial.

Desse modo, desde o início do século XVIII a presença britânica na região platina tornou-se mais efetiva. As autoridades do Vice-Reino do Rio da Prata freqüentemente registravam a presença de corsários ingleses nessa parte do Atlântico, os quais, segundo eles, contavam com a proteção dos portugueses. A fiscalização espanhola não conseguia coibir o contrabando "institucionalizado", apesar dos incentivos e apelos aos funcionários metropolitanos sediados na região. Há várias instruções da Audiência de Buenos Aires para a fortificação do porto na tentativa de barrar as investidas britânicas. Em cédula de 24 de fevereiro de 1802, a Audiência concedeu o título de "Fiel y Generoso" aos índios de Casapa, intendência do Paraguai, "por su actuación en la guerra contra la Inglaterra."3

$\mathrm{Na}$ medida em que os ingleses consolidavam suas posiçôes nas colônias espanholas da América, especialmente na parte meridional, buscavam na Europa a preferência nas relações com Portugal. Diante da nova con- 
juntura européia, o padrão da política externa portuguesa entre 1800 e 1801 traduzia uma perda de flexibilidade e maior rigidez na defesa dos interesses pró-britânicos. Esta menor flexibilidade resultou no conflito que passou à História como a "guerra das laranjas", 4 quando a Espanha, em 29 de janeiro de 1801, assinou com a França uma convenção na qual a corte espanhola exigia aos portugueses uma definição sobre os seguintes pontos: "que se fechassem os portos portugueses aos navios de guerra e de comércio da Grã-Bretanha, bem como a seus corsários, ficando aberto às frotas francesas e espanholas; e que se concedesse indenização pedida anteriormente, e mais compensaçōes financeiras a estipular." ${ }^{\text {Ap }}$ Apesar de Carlos IV ter retirado do ofício que envia a Dom João a cláusula que previa a perda de parte do território português, a negociação não se efetiva e, em 27 de fevereiro, a Espanha declara guerra a Portugal.

Com a ameaça do conflito na Península, dom Rodrigo de Souza Coutinho enviou correspondência ao Vice-Rei do Brasil ordenando que, caso houvesse guerra entre Portugal e Espanha, Buenos Aires e Montevidéu deveriam ser invadidos por tropas portuguesas. Ordenou, também, o reforço das guarnições do Rio Grande do Sul e Santa Catarina. No entanto, a invasão de terras espanholas vinha sendo preparada, mesmo antes da declaração de guerra, pois, desde 5 de março de 1800, o coronel Joaquim Xavier Curado governava Santa Catarina planejando a ocupação das províncias platinas. O coronel Curado coordenou um trabalho secreto de investigação sobre o arsenal e contingentes militares existentes no Vice-Reino do Rio da Prata. Seu relatório é extremamente minucioso, passando ao gabinete português não apenas informações estratégicas, mas, também, plantas de fortaleza e quadros estatísticos dos contingentes espanhóis.

A invasão de Portugal por tropas francesas com o apoio da Espanha em certa medida animou as pretensóes portuguesas e britânicas, uma vez que a invasão lusa às colônias espanholas não enfrentaria mais o constrangimento do confronto com os Borbón, pois o rei da Espanha apoiava Napoleão na invasão de Portugal. Assim, a expansão da fronteira podia ser justificada como represália à política francesa na Europa.

Essa possibilidade foi cogitada também pelo lado espanhol, pois tão logo soube da chegada da Corte portuguesa no Rio de Janeiro, sob a pro- 
teção inglesa, a administração vice-reinal enviou agente ao Rio Grande do Sul "para que com la cautela correspondiente se impusiese de todo quanto alli ocurria". "Entretanto, apesar do relato do informante Luis Larrobla não conter nenhuma notícia alarmante, ele assinalava que "La opinion bulgar es que dicho Principe pasará letras a la america Española para titular-se Emperador de toda ella". 7 É provável que a pretensão portuguesa, na época, não chegasse a tanto. Desejar todo o império espanhol seria político e militarmente inviável, a não ser através de uma nova União Ibérica, fato que naquele momento não poderia ser considerado viável uma vez que a Espanha tinha um rei no poder e também um herdeiro legítimo ao trono.

Por razões estratégicas, a execução do projeto luso-inglês para o Rio da Prata devia ser implementado imediatamente após a chegada do príncipe regente ao Brasil. As informações enviadas por Xavier Curado possibilitavam uma entrada segura em terras espanholas. Não é de estranhar, então, que, tão logo a Corte tenha-se instalado no Rio de Janeiro, dom Rodrigo desse andamento ao plano de invasão, mesmo antes de ter notícias sobre a emboscada de Bayona, que resultou no aprisionamento de toda a família real espanhola por Napoleão Bonaparte e a ascensão de José Bonaparte ao trono da Espanha. Inicialmente, dom Rodrigo pretendeu tentar convencer a burocracia colonial das vantagens da anexação daquelas províncias ao império português. A decisão voluntária das lideranças locais evitaria os custos de uma operação militar e neutralizaria possíveis protestos diplomáticos provenientes da Corte espanhola. Possivelmente, o relatório de Xavier Curado também sugeria tal estratégia, pois foi com base nos dados enviados por Curado a dom Rodrigo que se planejou a ocupação da região.

Usando o pretexto de comunicar ao Cabildo de Buenos Aires a chegada do príncipe regente ao Rio de Janeiro, o conde de Linhares enviou, no dia 13 de março de 1808, ofício aos cabildantes, criticando os reis da Espanha pela

sujeccion de la Monarquia Española en Europa a la Francia, y la casi entera aniquilasion de la misma [e oferecendo a proteção do príncipe a todo o vicereinado, porém, ] em caso que estas proposiciones amigables, y dirijidas solamente a evitar toda efusion de sangre, no sean oidas, entonces su Alteza Real sera obligado à obrar en comunidad con su poderoso Aliado, y con los grandes y fuertes medios 
que la Probidencia deposito en Sus Reales manos, y tal bes a ver con dolor el glorioso y esperable suceso de sus armas, y a considerar con lastima que Pueblos unidos por estrechos vinculos de la misma Sagrada Relijion, por las mismas costumbres y por el idioma que es casi el mismo se buelban enemigos, y sacrifiquen sus mas Sagrados intereses. Usted que compone el Cavildo, que es el Padre de la Patria debe tomar estas proposiciones en la mas seria considerasion y queriendo someterse a la proteccion y vasallaje de Su Altesa Real deve por otro iqual oficio proponer las/ condiciones y medios que el Cavildo juzgare combeniente para la reunion de estos Paises, vajo el dominio de un tan grande Principe, de que resultara su felicidad, y la de los Pueblos que con mas justo título nombraran entonces à Usted Padre de la Patria. ${ }^{8}$

O ofício português demonstra que a atitude da Corte do Rio de Janeiro é um ultimatum. O conde de Linhares tentou convencer o Cabildo da existência de identidades culturais entre as duas regiōes, eliminando assim qualquer dificuldade à anexação. $\mathrm{O}$ ponto mais controvertido do documento é o fato de dom Rodrigo reconhecer no Cabildo poder de decisão sobre a questão da adesão ao império português. Tal afirmação induz uma série de indagaçôes. O reconhecimento dos cabildantes como "pais da pátria" implica em negação da soberania espanhola naquelas províncias. Pode ser que a atitude do conde de Linhares se baseasse no fato de ter a Espanha declarado guerra a Portugal e, a partir daí, todos os acordos e tratados seriam considerados nulos pelo gabinete de dom João. Ou mesmo, como recomenda dom Rodrigo ao vice-rei do Rio de Janeiro - quando manda invadir Buenos Aires e Montevidéu —, que a resposta à guerra peninsular fosse dada na América, precisamente a região mais disputada pelo império português.

Confirmando a decisão de dar continuidade a uma política externa agressiva, o gabinete português no Rio de Janeiro, dois dias depois de enviar correspondência ao cabildo, ordenou que Joaquim Xavier Curado entrasse novamente em território espanhol, obedecendo às seguintes instruções:

Tres são os objectos que Vmce deve ter em vista na conformidade das Reas Ordens, q. The comunico: o 1- he conseguir ser admitido em Monte Video e Buenos Ayres, e este ponto $q$. he o mais essencial, poderá vencelo per si, e por via do governador do Rio Grande, propondo a negociação de q. vai encarregado para 
segurar a continuação do Comercio, na forma, que se esta praticando (...) 2- he tentar od governadores para o fim de unir aqueles paises ao Real Dominio, o que seria muito feliz, pois evitaria toda outra ulterior contenda. $O 3$ he o exame e conhecimento verdadeiro do voto da Nação Hespanhola, e da Opinião Pública sobre entragarem-se ao Governo Português, e em qualquer cazo o conhecimento do estado da Força Pública em Soldado, Officiais, Munições, q. tem, e ocupa o Rio da Prata). ${ }^{9}$

Xavier Curado se dirigiu para a vila de São Pedro do Rio Grande para cumprir sua nova "missão" em terras espanholas.

Enquanto Xavier Curado se preparava para tentar cooptar a administração colonial do vice-reino platino, no Rio de Janeiro o conde de Linhares investia em investigações que possibilitassem consolidar a "missão Curado". O ministro tem conhecimento da presença na cidade de um grupo de refugiados portenhos que havia apoiado o general Berresford, quando tenta ocupar o Rio da Prata. O ministro deu ordem ao encarregado da Justiça para que mantivesse o grupo sob vigilância. As diligências da polícia acabam descobrindo um grande "trunfo" para dom Rodrigo: encontrava-se clandestino no Rio de Janeiro, tentando conseguir passaporte para Buenos Aires, um oficial do exército espanhol, irmão do vice-rei de Buenos Aires, Santiago de Liniers. Segundo declaração do próprio conde de Liniers, ele saiu secretamente de Lisboa em um navio mercante com o nome português de Enrique Josef de Gorvera, como contador da embarcação. Chegando ao Rio de Janeiro, permaneceu incógnito até ser descoberto pela polícia da Corte.

Tão logo o Gabinete de dom João tomou conhecimento da presença do oficial espanhol na cidade de forma irregular, dom Rodrigo manda prendê-lo e ordena que o levem ao palácio. Em seu depoimento ao irmão, o conde relatou o encontro que teve com dom Rodrigo na presença do monarca:

La conferência principió por protextaciones generales, del deseo de vivir en Paz con nosotros, a las quales respondi que nuestro deseo seguramente era el mismo; entonces dijo que se esperaban pruebas de ello, y que S.A.R. habia resuelto de encargarme de las negociaciones relatibas a este objeto. ${ }^{10}$

O diálogo prossegue com a discussão sobre os ofícios trocados entre os dois governos e sobre a soberania espanhola e paz na região. O conde de 
Liniers critica a "missão Curado", "Hablando á V.E. con franquesa temo mucho que el negociador, que se ha enbiado al Sur (el Sr. Curado) no dañe mucho el trabajo pasifico que hademos aqui". ${ }^{11}$ Dom Rodrigo nega que tenha enviado o brigadeiro Xavier Curado como negociador formal, e realmente não o fez. As atividades do brigadeiro Curado eram de outro teor. Seguindo em seu depoimento, o conde de Liniers assinala que, na medida em que ele argumentava em favor da dinastia de Borbón, dom Rodrigo alterava o rumos da conversa:

A este punto, ya no fue un Dialogo, pero si un bemente discurso de Dn. Rodrigo durante el qual me fue imposible decir una palabra: este discurso fue una mescla de Amenazas, y pruebas de seduccion para ti, y para mi; el Ministro no se explicaba claramente pero comprehendi mui bien que con la esperanza de ganarme ó de intimidarme, tenía todavia la de que, el temor de una doble guerra con los Ingleses, y los Portugueses reunidos llebarian puede ser nuestras Colonias à hecharse en los brazos del Portugal. ${ }^{12}$

As argumentações de dom Rodrigo se sustentam nas mesmas bases do ofício que manda ao Cabildo de Buenos Aires: ausência de soberania espanhola. No entanto, neste momento o argumento ganha força pelo fato de estar a Espanha sob o domínio de Napoleão. O conde de Linhares tentou convencer Liniers de que a Espanha não existia mais, e que provavelmente seria toda dividida, resultando em graves conseqüências para as colônias. Daí, a melhor saída seria a união com Portugal. As negociações duraram quatro dias — de 23 a 26 de março de 1808 - mas, ao que parece, não conseguiram convencer o irmão do vice-rei, que em seu relatório, de forma implícita ou explícita, critica a postura de dom Rodrigo, e mesmo do príncipe regente, em relação à política implementada nas colônias espanholas.

O conde de Linhares acompanha passo a passo o desenrolar das atividades de Xavier Curado e mantém correspondência sistemática procurando prover o brigadeiro de todo o necessário para o sucesso da "missão". Em uma de suas cartas a Xavier Curado, comenta a presença do conde de Liniers na Corte, "qui se acha doente o Irmão do Vice Rei Liniers, a quem S.A.R. pedio que se demorasse esperando q.elle aqui, e Vmce em Buenos Aires poderão acelerar todas as Negociações" ${ }^{13}$ O sigilo é a arma da diplomacia 
de guerra e mesmos os indivíduos mais confiáveis não conhecem toda a verdade. Dom Rodrigo era um negociador experiente, participou de imbricadas relações diplomáticas nos tempos Lisboa. Assim, escondia de Xavier Curado a real situação do conde de Liniers, que se encontrava como refém, para, na hora oportuna, servir de peça de negociação. É exatamente isto que acontece. Meses depois, em 27 de julho de 1808, dom Rodrigo informou o brigadeiro da chegada do irmão de Liniers: "vai ahi em Navio Parlamentar, e que não será entregue pelos Ingleses sem que lhes conste, q. V.S. está já de volta ao nosso território". ${ }^{14}$

Xavier Curado, seguindo rigorosamente o plano de dom Rodrigo envia ofício ao vice-rei e ao governador de Montevidéu com pedido de permissão para ir a Buenos Aires tratar de "comercio de estas Províncias, y estrechar mas os vinculos de amistad y alianza de nuestro Augustos Soberanos". Pede ao governador que facilite o que for necessário para a viagem, "algun coche, $u$ otro carruage, y las cavalladas que pidiere". No mesmo dia 26 de abril de 1808 , o vice-rei envia ofício a Joaquim Xavier Curado e ao governador de Porto Alegre, dom Paulo José da Silva Gama, acusando o recebimento da solicitação de entrada em Buenos Aires dos representantes do príncipe regente e informando que serão fornecidos todos os auxílios necessários para o desembarque na capital do Vice-Reino.

Obtida a indispensável permissão do vice-rei, Xavier Curado vence a primeira etapa do plano e segue viagem para Montevidéu. Apesar de toda cautela e experiência de Xavier Curado como agente de informaçóes, as autoridades coloniais do Vice-Reino desconfiam de sua presença em território espanhol e o interpelam sobre suas atividade. Curado envia ofício ao cabildo de Buenos Aires informando que estava em condição de enviado especial do príncipe regente para tratar e incrementar o comércio entre as duas nações. $\mathrm{O}$ documento do então coronel Curado chega às mãos dos calbildantes na mesma época do ofício de dom Rodrigo. A coincidência desses dois ofícios consolida as suspeitas dos membros do Cabildo dos perigos que representava a presença da família real portuguesa em terras americanas.

No dia 27 de abril, o presidente do Cabildo de Buenos Aires convoca reunião extraordinária e, durante dois dias, são discutidas medidas a serem 
tomadas em conseqüência da ameaça luso-inglesa. Inicialmente, faz-se um levantamento das necessidades financeiras e militares a fim de encaminharse pedido de auxílio não só à Espanha, como às províncias vizinhas, especialmente ao Vice-Reino do Peru. Em dois pontos os ofícios são comentados declarando-se que

haviendo leido com reflexion el oficio del Brigadier Dn Joaquim Xavier Curado (Embiado por el Principe Regente) (...) los hallaraon disconformes em su espiritu, indicandose em el de este ciertos obgetos que no pueden fiarse a la pluma; cuias razones aunque en confuso coincidan con el oficio del Ministro Coutinho; en cuyo concepto y en el de tenerse noticia de que aquel Embiado trahia especial encargo de imponerse de nuestro Estado y que al efecto conducia en calidad de Edecanes de Ingenieros; juzgaron los Señores era de necesidad el que se le combenciese àl Señor Governador y capitan Gral no permitiese pasar de modo alguno à esta capital aquel Embiado, antes por el contrario se le detubiese en Montevideo (..)... Que en vista de la capciosidad de los oficio s del Brigadier Curado y Teniente Gral. da Silva Gama, y las manifestas perfidas miras de aquella corte, descubiertas por el Tenor del ficio de su Ministro Coutinho ya no quedaba la menor duda que aquella Nacion y su Govierno nos era declaradamente enemigo. ${ }^{15}$

A partir da constatação de que a Corte do Rio de Janeiro era um inimigo real, os membros do Cabildo decidem partir para o confronto, e ordenam ao governador de Montevidéu que detenha Xavier Curado, e que não lhe permita entrar em Buenos Aires. Para isso davam amplos poderes ao Governador

para que deteniendo en aquella Plaza al Brigadier Curado (...) oise su mision, satisfaciese á ella sin demora y le despachase sin permitirle transladarse à esta que se combencia de la mal feé y miras hostiles de aquel Principe [Concordam por uma atuação mais ofensiva antecipando o confronto, e destinam] 200 voluntarios à ocupar à viba fuerza el Rio Grande de San Pedro, unico arbitrio para ebitar las correrias que los Portugueses harian en la Campaña Oriental (...) que para Gefe de aquella Expedizion podia nombrarse àl Coronel Dn. Xavier de Elio que sus conocimientos militares y actibidad era mui á proposito para un golpe de mano...(p.19) Propunham ainda que a invasão fosse auxiliada por buques de guerra pois consideravam que...la Expedizion no debia solo limitarse à la ocupacion del Rio Grande sino tambien à la del Rio Pardo, y á puntos distantes entre si las atenciones de los Portugueses y ebitar su reunion expediria la 
correspondientes Ordenes para que al mismo tiempo se les atacase por la Provincia de Misiones y á sus estabelecimientos de Coimbra y Matogroso. ${ }^{16}$

Com a proposta de invadir todas os focos de estabelecimentos portugueses na fronteira platina, os membro do Cabildo de Buenos Aires assinam uma declaração de guerra. A partir dessa decisão, o Cabildo emite uma série de correspondências solicitando ajuda militar e financeira. Os cabildantes consideram a guerra viável, pois a avaliação que fazem das forças luso-inglesas os levam à conclusão de que elas ainda são precárias, porque, se assim não fossem, já teriam tomado alguma medida mais ofensiva. $\mathrm{Na}$ verdade, a argumentação dos cabildantes e a própria decisão de invasão de terras brasileiras é equivocada. Em primeiro lugar, a conjuntura internacional não permitia que a Espanha enviasse tropas. A crise no interior da própria Casa de Borbón, que teve como desfecho a abdicação de Carlos IV em favor do filho Fernando VII, demonstrava que as preocupações com o destino da metrópole impediam qualquer auxílio às colônias. Em segundo, desde os meados do século XIX as rebelióes indígenas ocupam e desgastam os exércitos coloniais, especialmente no Vice-Reino do Peru, onde a revolta Tupac Amaru impôs às tropas do Vice-Reino dois anos de guerra. Sendo assim, as províncias também não tinham muito a oferecer ao Rio da Prata.

Ao que parece, apesar da correspondência de Santiago de Liniers a Xavier Curado estar datada de 26 de abril de 1808, possivelmente o vicerei ainda não havia recebido o relatório do irmão. Entretanto, é estranho que as notas do vice-rei, com apenas um dia de diferença da reunião do Cabildo - que coloca Xavier Curado sob suspeita - não demonstrem tal conhecimento. Ou as informaçóes de Santiago de Liniers estavam defasadas em relação às do Cabildo, ou o vice-rei estava dissimulando e tentando "ganhar terreno" para agir com maior segurança. Não é plausível considerar que Santiago de Liniers não soubesse o que estava ocorrendo no Cabildo, até porque os cabildantes decidiram indicar o governador de Montevidéu, Javier Élio, para comandar a expedição em terras brasileiras.

Quadro dias depois da reuniāo do Cabildo, Santiago de Liniers recomendou a Javier Élio que tratasse Xavier Curado como representante da Coroa portuguesa. No final da nota faz uma observação um tanto ambí- 
gua: "Obrando en todo con la precaucion y reserva que corresponde, para no exponer las determinaciones, ni la seguridad de estas Provincias". ${ }^{17}$ A nota que o vice-rei remete a Xavier Curado, no mesmo dia da anterior, sugere a existência de suspeitas em relação ao agente português. Alegando motivos de saúde que o obrigam a retirar-se ao campo, Santiago de Liniers informa a Xavier Curado que autorizou o governador de Montevidéu a recebê-lo para tratar dos assuntos de que estava encarregado.

De acordo com a jurisdição diplomática do Antigo Regime, a burocracia colonial não tinha autoridade para tratar de negócios que ferissem ou alterassem as relaçóes internacionais e, especialmente, aquelas que interferissem no pacto colonial. Xavier Curado alegava que tinha poderes para tratar do comércio entre o Brasil e o Vice-Reino do Rio da Prata. Portanto, se a regra fosse cumprida à risca, as negociações teriam de ser feitas com o governo da Espanha. Considerando o fato de a Espanha estar invadida e o não reconhecimento por parte do vice-reinado do novo rei José Bonaparte, o interlocutor neste caso só poderia ser o vice-rei. Ao entregar a um governador o poder de negociar com um representante estrangeiro, Santiago de Liniers desqualificava qualquer acordo que se estabelecesse. Uma correspondência cruzada entre membros do Cabildo sugere que a decisão de Liniers de não permitir a entrada de Xavier Curado em Buenos Aires foi uma posição tirada em conjunto com o Cabildo.

Os cabildantes não demoram a responder o ofício do gabinete português. Após fazerem inflamada declaração de fidelidade ao rei Fernando VII, concluiam que

los ultrajes de tanto vulto. Y sobre todo debe estar V.E. persuadido, y debe estarlo también su Alteza Real el Principe Regente....Si en otros tiempos, en diferentes épocas y aun en nuestros dias han dado(habitantes de la America) al Mundo pruebas irrefragables de lo que puede el valor inflamado por el entusiasmo de la lealtad, derramarian gustosos hasta la ultima gota de sus sangre antes de permita que se desmembre de la Corona de España una minima parte de estas vastas posesiones. ${ }^{18}$

A crise entre a Corte do Rio de Janeiro e as autoridades do Vice-Reino do Rio da Prata se aprofundavam e o conflito parecia iminente. Ao receber a carta do irmão, Santiago de Liniers ordenou ao governador que 
Joaquim Xavier Curado fosse mandado para Buenos Aires sem parar em Montevidéu. Avisava ter enviado ao porto de Maldonado o Bergantim Belén para que o conduzisse diretamente à capital do Vice-Reino. Com informações que recebeu do irmão Santiago de Liniers, passou a exigir as credenciais de Xavier Curado que o autorizavam como negociador do príncipe regente. Em resposta às exigências do vice-rei Xavier Curado diz que "me considero legitimamente autorizado, e instruído dos objetos de minha comissão; como Delegado do Goberno Portuguez; que não tenho cartas: as quaes se forem necesarias virão prontamente". ${ }^{19}$ Santiago de Liniers recorre ao Derecho de Gentes para interpelar Xavier Curado sobre a intenção de estabelecer negociações sem credenciais, lembrando-o de que não se pode tratar coisa alguma sem os legítimos poderes. $\mathrm{O}$ vice-rei recomenda ao governador de Montevidéu que mantenha o brigadeiro Curado sob maior segurança, na qualidade de refém, até a chegada de seu irmão do Rio de Janeiro.

A grave crise diplomática gerada pela falta de credenciais de Xavier Curado - que demonstrava, assim, não estar em missão oficial — colocava-o sob suspeita de desenvolver atividades clandestinas. Por outro lado, as notícias que recebeu do irmão fizeram com que Santiago de Liniers enviasse correspondência ao Rio de Janeiro criticando a "missão Curado" e exigindo a libertação do irmão. Porém, talvez para evitar a imediata eclosão de um conflito armado, concluía reiterando suas intençôes de manter a paz.

Casi al mismo tiempo que el Governador del Rio Grande y el Brigadier Joaquin Xavier Curado me aseguraban en cartas de 8 y 14 de abril de este año, que el ultimo estava autorizado por V.A.R. para tratar con este Govierno asuntos de comercio y de interes reciproco que consolidasen los vinculos y enlazes de estos $y$ esos Paises, recebió esta Ciudad un oficio de esa corte que indicaba medidas muy opuestas á los mencionados principios... despues que llegó á Montevideo (Brigadeiro Curado) me avisó se hallava sin credencial ni poderes que legitimasen su mision: sin embargo de este inesperado incidente devo declarar á V.A.R. como una contextacion directa y positiva a las dos citadas cartas que seré imbariable en mantener la buena armonia y plan de sinceridad que ha reinado hasta aqui entre ambos establecimientos. ${ }^{20}$

Entretanto, dom Rodrigo não parecia estar disposto a negociar. Com a notícia da invasão francesa à Espanha, o conde de Linhares encontrou 
um outro pretexto para exigir a preponderância portuguesa nas províncias platinas. Em carta de instrução a Xavier Curado, ordenou-lhe que informasse ao vice-rei que seria indispensável que se tomassem todas as medidas para impedir que os franceses desembarcassem no Rio da Prata e, assim, perturbassem a paz na fronteira com o Brasil. Era categórico ao afirmar que

exige q. o Exm. Vice-Rey lhe entregue com o consentimento do Povo Espanhol a guarda da margem septentrional do Rio da prata, athe a paz Geral, e q. com condição S.A.R. se encarrega de conservar a Paz com os dominios Hespanhóis(...) q. se esta proposição não for julgada admissivel tem ordem de retirar-se notificando-lhes, qu. S.A.R. não ficara responsável diante de Deus das tristes consequencias de uma negação tão alhêa de toda boa razão. ${ }^{21}$

Ao receber esta correspondência, Xavier Curado enviou à Corte do Rio de Janeiro detalhado relatório sobre suas diligências e sobre as condições de uma possível invasão. O texto é longo mas elucidativo, não somente pelas informações oficiais solicitadas pelo gabinete de dom João, mas, especialmente, pela visão que apresenta da sociedade platense às vésperas da independência.

Hoje fazem 31 dias, que cheguei a esta Praça (...) pois devo afirmar a $V$. Exellencia, q. apezar das minhas mais serias deligências não tenho encontrado e nem espero encontrar hum homem com autoridade, e influencia que de quem possa esperar hum felix exito as nossas pretençôes (...) aqueles que na aparencia de achão revestidos do poder publico são fantasmas da grandeza, muitas vezes insultados, e sempre sugeitos ao Povo, cuja anarchia he tão excessiva, e absoluta que se atreve a objetar todas as dispoziçoens, e ordens dos que governão (...) $O$ Cabildo tem sobre os Povos algum poder, porem he tão limitado, que apenas se estende sobre aquelles asuntos, que podem lizongear os seus interesses particulares; (...) O Povo he total, e declaradamente inclinado a República livre, para cujo fim ja se lembrão de planos em Buenos Ayres. ${ }^{22}$

A anarquia dos poderes coloniais observadas pelo brigadeiro Curado pode ser justificada em virtude da situação da Espanha sob o domínio francês. Com a ausência do poder legítimo na metrópole, a burocracia e os órgãos representativos do poder espanhol sofrem uma crise de legitimidade. O mesmo ocorre na Península. As juntas de governo criadas nos diver- 
sos reinos, para contraporem-se ao governo de José Bonaparte, pleiteiam a hegemonia e o poder, umas sobre as outras. No império espanhol o poder se sustentava com base na relação contratual da Coroa espanhola com seus súditos, uma relação fundamentada em compromisso pessoal, do tipo vassalagem. No caso dos súditos americanos, o compromisso é com a Coroa de Castela. O vazio no poder significa o rompimento do compromisso e, portanto, o direito de não aceitar o rei invasor, recaindo então o poder nas mãos dos vassalos. Tanto na América como na Península a indefinição sobre quem detém o poder gera o que Curado entende por anarquia.

Joaquim Xavier Curado informou o conde de Linhares das práticas que vinha usando para angariar apoio do cabildo:

Ainda apesar destas vicissitudes, pretendi achar meyos de chamar ao nosso partido os referidos Cabildantes, servindo-me de ofertas bastante capazes de nutrir os seos ambiciozos projetos, porem encontrei a certeza, do que praticarão com o general Inglez Withlok, que tendo comprado todo o Cabildo por avultosas somas, e contando com a promessa de hum grande numero de homens de primeira classe (...) achou-se enganado, e chegou ao extremo de Capitular. [Sobre a possiblidade de ocupação da região sugere que] só resta o meyo da força a qual parece, que deve ser muito superior para dicidir prontamente a favor das pertençoens de Sua Alteza Real, e conservar em respeito a Nação. Com gosto vejo no referido Oficio q. V. Excellencia me anuncia um exército de 20 mil homens. Este numero de Tropa, nunca menos, antes mais se for possivel, será suficiente para felicitar os nossos projetos. O mesmo Real Senhor foi servido dizer-me, que estimaria poupar o sangue humano. Pois o meyo mais facil de conseguir esta fortuna he aprezentar hua força minimamente superior, que fassa emudecer os Hespanhoes, e emudecer seos projetos. [Concluiu declarando que] $O$ voto da Nação Hespanhola a nosso respeito em nada he favorável: reina hua conhecida rivalidade (..) Posso afirmar a v. Excellencia, que esta Praça deve ser tomada de asalto, ou bloqueo de Mar, e terra. ${ }^{23}$

Assim, de acordo com o parecer do brigadeiro Curado, a possibilidade de uma invasão pacífica, ou seja, com a colaboração dos criollos, parecia inviável. A única chance de conquistar as províncias de Vice-Reino do Rio da Prata era uma guerra com grande aparatus bélico. Em fins de 1808, cumprindo o programa estabelecido por Xavier Curado, a legião de São Paulo foi mandada, em maior segredo, para o Rio Grande do Sul. 
Joaquim Xavier Curado procurava manter a Corte do Rio de Janeiro informada de tudo que acontece no Vice-Reino. Em agosto, por exemplo, comunicou ao conde de Linhares a chegada a Montevidéu de delegados franceses com despachos de Napoleão para Liniers, informando da abdicação de Carlos IV em favor de Jose Bonaparte e exigindo a aclamação do rei também nas colônias. Para que essas ordens fossem cumpridas, estava sendo preparada uma expedição com 10.000 homens para guarnecer as margens do Rio da Prata. Em carta datada de setembro, Curado informava o príncipe regente de que, em Montevidéu, Fernando VII fora proclamado rei e os emissários franceses foram banidos da cidade.

$\mathrm{Na}$ Corte do Rio de Janeiro, a descoberta da ação secreta do brigadeiro Xavier Curado, e a contundente reação das províncias, desencadeou veemente protesto da princesa Carlota Joaquina. Em carta a dona Carlota Joaquina, Santiago de Liniers denunciou a ação do brigadeiro Joaquim Xavier Curado no Rio da Prata.

O mariscal de Campo Don Joaquim Xavier Curado quien despues de haber permanecido mas de dos meses en la Plaza de Montevideo sin ningunas credenciais de V.A.R., las acababa de ricibir por conducto del Ministro de las relaciones Exteriores Dom Rodrigo de Souza Coutinho se adelanta á hacerme unas prpuestas tan atentativas ál Derecho Natural y de gentes, y tan contradictorias con lo que se digna V.A.R. comunicarme que sin este apreciable requisito hubera tornado semejante insinuacion por uno formal declaracion de Guerra. ${ }^{24}$

A princesa Carlota Joaquina reage prontamente às investidas do marido nos domínios de seus país e, em carta a dom João, considera a "missão Curado" uma violação das leis espanholas pedindo que ordenasse a sua retirada imediata da região:

Espero que una sospecha fundada existente y positiva, qual tiene el Govierno y Pueblo de Buenos Aires de la conduta del expresado Curado, sera bastante para que V.A.R. lo mande retivar de los dominios de S.M.C., en donde no puede existir, sin contravenir a las leyes dela Monarquia Eapañola, por quanto estas prohiven a los Virreys y demas Jefes tener intelligencias con Potencia o Principe alguno, debiendose estos en sus negocios y pretenciones entender directamente con S.M.C. o con el que represente sus vezes en la Corte de España. Poe esto és que en las colonias de S.M.C. (ni en las de Soberano alguno) no se han admitido hasta 
haora, ni embajadores, ni Plenipotenciarios, ni embiados, y lo que aun es mas en la America Española, ni los Consules son admitidos. ${ }^{25}$

A chegada de Sidney Smith ao Rio de Janeiro e as notícias da queda da monarquia espanhola vão mudar radicalmente os rumos da política portuguesa em direção ao Prata. O projeto luso-inglês de anexação das províncias platinas começa a apresentar dificuldades, principalmente por três motivos: em primeiro lugar, porque a guerra de libertação contra a Napoleão selou um acordo entre a Espanha e a Inglaterra, e assim qualquer idéia de invasão militar aos domínios espanhóis deveria ser abortada; em segundo, porque a separação das colônias da Espanha era considerada por Lorde Strangford o caminho mais vantajoso para o comércio britânico, e, em terceiro, porque com o juramento da maioria das juntas coloniais de fidelidade ao rei Fernando VII, a invasão teria de ter caráter militar, como adverte Xavier Curado no relatório que enviou a dom Rodrigo. Entretanto, neste momento, Portugal já não podia mais contar com o apoio das tropas britânicas.

Por outro lado, não interessava nem a Portugal nem a Inglaterra perder a supremacia nas províncias platinas. A saída encontrada para uma ocupação "branca" foi arquitetada pelo almirante inglês Sidney Smith, comandante da frota naval britânica no Rio de Janeiro. O plano de Sidney Smith previa a instalação de uma monarquia tendo a infanta de Espanha Carlota Joaquina como regente. O gabinete português, claramente desfavorável a Carlota Joaquina, recebeu a proposta com desconfiança, mas, diante da possibilidade de ter não somente o Vice-Reino do Rio da Prata sob o domínio português, mas toda a América espanhola, dom Rodrigo, ao vislumbrar a possibilidade de uma nova União Ibérica, além de concordar com o projeto, solicitou ao duque de Palmela que trabalhasse pela indicação de Carlota Joaquina à regência da Espanha — uma vez que na península parte da nobreza espanhola defendia esta solução.

Na verdade, não era propósito do conde de Linhares entregar a Carlota Joaquina o poder. Tanto assim que, imediatamente, propôs como alternativa o nome de dom Pedro Carlos, primo de Carlota Joaquina e sobrinho de dom João, que por ter sido criado na Corte de Bragança, era mais afeito aos interesses portugueses. A fim de consolidar a posição do infante no pleito 
à regência espanhola, o conde de Linhares articulou o casamento da filha de dona Carlota com dom João.

A reação mais efetiva ao projeto da regência partiu do embaixador inglês Lord Strangford, que nunca foi favorável à participação da princesa em assuntos diplomáticos, pois partilhava da opinião do comandante das forças inglesas na Espanha, o duque de Wellington, de que a posição política de Carlota Joaquina era desfavorável aos interesses da Inglaterra. Assim, passou a criar entraves a todas as medidas políticas que pudessem favorecer dona Carlota. Ao mesmo tempo, lorde Strangford procurava desencorajar dom João quanto ao projeto de invasão do Rio da Prata, o que levou à especulação sobre sua preferência em favor da constituição de uma República, mais do que qualquer outra das alternativas cogitadas.

Confirmando as suspeitas da Corte portuguesa, o vice-rei do Rio da Prata, Hidalgo de Cisneros, remeteu ao marquês de Casa Irujo, embaixador espanhol no Rio de Janeiro, queixas contra os britânicos reclamando do apoio que Strangford dava a Ana Perichon de O'Gorman, que havia sido amante de Santiago de Liniers, e que, segundo ele, estava sendo protegida pelos ingleses na Corte do Rio. Apresentava documentos que comprovavam a colaboração da Corte do Brasil e do embaixador inglês. $\mathrm{O}$ marquês de Casa Irujo era outro que estava convencido de que o comportamento do ministro inglês favorecia a causa republicana e advertiu o governo espanhol sobre o fato: "La Gran Bretaña espera mas liberalidad en el sistema Mercantil de una o de varias Repúblicas que dependan de ella, que de un Govierno Monárquico". ${ }^{26} \mathrm{O}$ gabinete de dom João também não tinha dúvidas de quais eram as intenções de sua maior aliada. Era evidente que a Inglaterra já não fazia mais questão da parceria lusa em seus projetos no Prata. A opção pela independência das províncias sob a influência britânica inquestionavelmente era a melhor solução.

O conde de Linhares não desistiu do projeto de anexação da Banda Oriental e, mesmo sem o apoio da Inglaterra, ordenou que Joaquim Xavier Curado permanecesse na fronteira e que, apesar das mudança na política internacional, continuasse mantendo-o informado de "toda a miudeza, axação de tudo aquillo q. para as Províncias do Rio da Prata possa notarse.” Em nota ao governador da capitania de Rio Grande, Xavier Curado 
deu instruções recebidas de dom Rodrigo: "que puzesse a tropa toda no melhor pé possível e que vigiasse cuidadosamente os movimentos dos Hespanhoes, e tivesse prompto uma força para enfrentar qualquer surpresa”. Numa outra correspondência da mesma época dom Rodrigo recomendou: "faça o favor do Gov. da Praça de Monte Video todas aquelas declarações que ele desejar, e q. sejam conducentes a comprovar sua honra e fidelidade." 27

Com a revolução de Maio de 1810, Joaquim Xavier Curado foi enviado para a capitania do Rio Grande do Sul ficando à disposição do governador, dom Diogo de Souza, que lhe deu o comando de uma das colunas do exército com a tarefa de conquistar a Banda Oriental. As dissidências entre Buenos Aires e Montevidéu, que permanecia fiel à monarquia espanhola, desencadeiam complicada política externa por parte do gabinete do Rio de Janeiro, em virtude da Corte estar dividida em três "partidos": a do conde de Linhares, que defendia a invasão militar; a de dona Carlota Joaquina, que apostava no fortalecimento do "carlotismo" para conseguir a regência da Espanha e governar, a exemplo de dom João, na colônia, e a de lorde Strangford, que sigilosamente apoiava a independência. Os permanentes confrontos entre essas três tendências resultaram muitas vezes em medidas contraditórias, especialmente em relação ao posicionamento do exército português disposto na fronteira — que recebia ordens de avanços e recuos, de acordo com a maior ou menor pressão de cada grupo.

Em 1811, dom João VI deu ordens ao exército na fronteira para que invadisse a Banda Oriental, atendendo ao pedido de socorro do então vicerei Javier Élio, na tentativa de frear a Junta de Buenos Aires que se rebelara contra o poder metropolitano, dando início a guerra de independência.

Joaquim Xavier Curado permaneceu na fronteira sul até 1820, quando, de volta ao Rio de Janeiro, foi nomeado Conselheiro de Guerra. Em 1822 comandou as tropas fiéis a dom Pedro I, derrotando as forças sublevadas do general Jorge Avilez. Em 15 de setembro de 1830 Joaquim Xavier Curado morree na capital do império sem ver concretizada a expansão definitiva do império português até a Banda Oriental do Rio da Prata. Projeto que será incorporado pelo império brasileiro, dando continuidade às guerras cisplatinas até o trágico desfecho da Guerra do Paraguai. 


\section{Notas}

${ }^{1}$ Joquim Xavier Curado, filho de João Gomes Curado e de dona Maria Josefa Pinheiro, nasceu no dia 1ํㅡㄹ de março de 1743 na Freguesia de Meia Ponte, estado de Goiás. Ficando órfão de pai partiu de sua cidade natal com destino ao Rio de Janeiro, onde pretendia habilitar-se para ingressar na universidade de Coimbra. A convite do conde da Cunha, deixou o seminário São José e entrou no exército como soldado nobre com apenas 21 anos. Embarcou com seu regimento para fronteira sul em virtude da invasão espanhola, incorporado à expedição comandada pelo general João Henrique Böhn, quando, segundo seus contemporâneos, praticou atos de bravura. No relatório que o vice-rei Luiz de Vasconcelos remeteu ao conde de Rezende é feita uma relação dos numerosos serviços prestados por Xavier Curado, sendo ele recomendado para substituí-lo no cargo de vicerei. Em 1797, o conde de Rezende apresentou-o a dom Rodrigo de Souza Coutinho com as melhores referências. No último período do governo do conde de Rezende foi nomeado governador de Campos. Deixando o cargo, seguiu para Europa no desempenho de outra função, "por demais importante", junto à Corte de Lisboa. Durante a viagem, a embarcação em que se encontrava foi aprisionada por um navio francês e, cumprindo ordem que recebera antes de partir, jogou ao mar toda a documentação que levava. Segue como prisioneiro para a baía de Biscaya, dali indo por terra a Lisboa com escala em Madri. Regressou ao Rio de Janeiro em 1800. Ver: Lago, Laurêncio. Brigadeiros e generais de D. João VI e D. Pedro I no Brasil. Dados biográficos, 1800-1831. Rio de Janeiro: Gráfica Laemmert. p. 83; Silva, A. Pretextato Maciel da. Os generais do exercito Brasileiro de $1822-$ 1898. Rio de Janeiro: T. I., 1906. p. 192.

${ }^{2}$ Tratado de Utrecht, 1715; Tratado de Madri, 1750; Tratado do Pardo, 1761 e Tratado de Santo Ildefonso, 1777.

${ }^{3}$ Levene, Ricardo (Org.). Cedulário de la Real Audiencia de Buenos Aires. Buenos Aires: Archivo Historico, 1942.

${ }^{4}$ Assim conhecida historicamente por seu caráter mais diplomático que bélico.

${ }^{5}$ Alexandre, Valentim. Os sentidos do Império. Questão nacional e questão colonial na crise do Antigo Regime português. Porto: Edições Afrontamento, 1993, p.122.

${ }^{6}$ Archivo General de la Nación. Politica lusitana en el Rio de La Plata - 1808-1815. Buenos Aires, 1961. 3 vols. Vol. 1, p. 6. (Coleção Lavradio).

${ }^{7}$ Idem, p. 8.

${ }^{8}$ Carta de dom Rodrigo de Souza Coutinho ao Cabildo de Buenos Aires. Rio de Janeiro, 15/02/1808. Arquivo Histórico do Museu Imperial: I-POB15.2.1808.

${ }^{9}$ Ofício de dom Rodrigo de Souza Coutinho ao Brigadeiro Joaquim Xavier Curado em 15/03/1808. Apud Acevedo, Walter Alexandre. A missão secreta do marechal Curado ao Rio da Prata (1808-1808). Revista do IHGB, Rio de Janeiro, jul./set. 1946, p. 175.

${ }^{10}$ Arquivo General de la Nación. p. 31.

${ }^{11}$ Idem, p. 37. 
${ }^{12}$ Idem, p.32.

${ }^{13}$ Carta de dom Rodrigo de Souza Coutinho a Joaquim Xavier Curado, 14/04/1808. Apud Acevedo, Walter Alexandre. Op. cit., p. 175.

${ }^{14}$ Carta de D. Rodrigo de Souza Coutinho a Joaquim Xavier Curado, 27/07/1808. Idem, p.177.

${ }^{15}$ Acordos Celebrados no Cabildo de Buenos Aires 27 e 28 de abril de 1808. Arquivo General de la Nación. p.15.

16 Idem.

${ }^{17}$ Nota do vice-rei ao Governador de Montevideu. Arquivo General de la Nación. p. 45.

${ }^{18}$ Resposta do cabildo de Buenos Aires ao conde de Linhares. Arquivo Histórioco do Museu Imperial: I-POB-1808.

${ }^{19}$ Nota do Brigadeiro Joaquim Xavier Curado al vice-rei D. Santiago de Liniers. 26/06/ 1808. Arquivo General de la Nación, p.50.

${ }^{20}$ Carta do vice-rei Santiago de Linier ao conde de Linhares. 28/07/1808. Arquivo General de la Nación, p. 20.

${ }^{21}$ Carta do conde de Linhares a Joaquim Xavier Curado. 27/07/1808. Acevedo, Walter Alexandre. Op. cit., p. 176.

${ }^{22}$ Ofício de Joaquim Xavier Curado a Rodrigo de Souza Coutinho.16/07/1808. Arquivo General de la Nación, p. 75.

${ }^{23}$ Idem, p. 76.

${ }^{24}$ Carta de Santiago de Liniers a dona Carlota Joaquina. Archivo Historico Nacional. Madri. Estado legado 5837, n. 38.

${ }^{25}$ Carta de Carlota Joaquina a dom João. Archivo Historico Nacional. Madri. Estado legado 5837 , n. 36.

${ }^{26}$ Carta do marquês de Casa Irujo ao vice-rei do Rio da Prata. 12/08/1809. Archivo General de Indias, Estado: 98 n. 18.

${ }^{27}$ Carta de D. Rodrigo de Souza Coutinho a Joaquim Xavier Curado. 06/12/1808. Acevedo, Walter Alexandre. Op.cit. p.178.

\section{Resumo}

$O$ artigo ressalta a politica externa bragantina para a região do Rio da Prata na época da chegada da corte portuguesa ao Brasil. Analisa a "missão" de Joaquim Xavier Curado como agente secreto da Coroa portuguesa nas províncias platinas no período de 1800 a 1808 . 
Dom Joaquim Xavier Curado e a política bragantina 183

\section{Abstract}

The article emphasize the external politics concerning House of Bragança in the river Plate, as soon as the real Portuguese family arrival at Rio de Janeiro. So, it analyses the mission of Joaquim Xavier Curado as a secret agent of the potuguese monarchy in the river plate regions, from 1800 to 1808. 